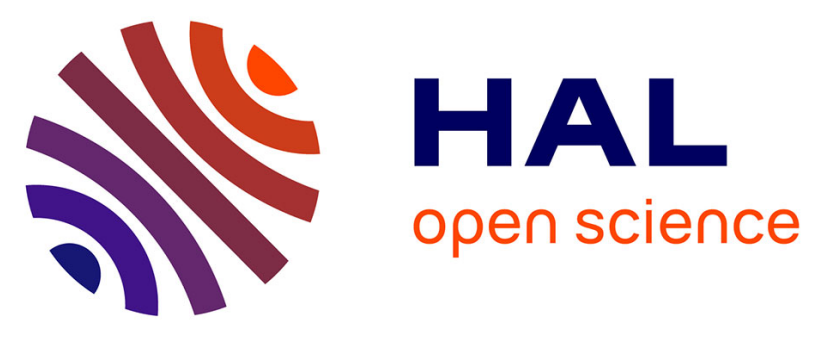

\title{
Language Understanding of the Three Groups of Connections: Management Innovation Dynamic Mechanism and Intelligent Driving Environment
}

\author{
Guangsheng Wang, Hanglin Pan, Xiaohui Zou
}

\section{- To cite this version:}

Guangsheng Wang, Hanglin Pan, Xiaohui Zou. Language Understanding of the Three Groups of Connections: Management Innovation Dynamic Mechanism and Intelligent Driving Environment. 2nd International Conference on Intelligence Science (ICIS), Nov 2018, Beijing, China. pp.235-242, 10.1007/978-3-030-01313-4_25. hal-02118836

\author{
HAL Id: hal-02118836 \\ https://hal.inria.fr/hal-02118836
}

Submitted on 3 May 2019

HAL is a multi-disciplinary open access archive for the deposit and dissemination of scientific research documents, whether they are published or not. The documents may come from teaching and research institutions in France or abroad, or from public or private research centers.
L'archive ouverte pluridisciplinaire HAL, est destinée au dépôt et à la diffusion de documents scientifiques de niveau recherche, publiés ou non, émanant des établissements d'enseignement et de recherche français ou étrangers, des laboratoires publics ou privés.

\section{(c)(1)}

Distributed under a Creative Commons Attribution| 4.0 International License 


\title{
Language Understanding of the Three Groups of Connections: Management Innovation Dynamic Mechanism and Intelligent Driving Environment
}

\author{
Guangsheng Wang ${ }^{1}$ and Hanglin Pan ${ }^{2}$ and Xiaohui Zou ${ }^{3[0000-0002-5577-8245] ~}$
}

${ }^{1}$ Chinese Academy of Social Sciences, No. 5, Jianguomen Inner Street, Beijing 100005, China

${ }^{2}$ Hangzhou Ziya Intelligent Technology Co., Ltd.

${ }^{3}$ Sino-American Saerle Research Center

949309225 @ qq. com

\begin{abstract}
The purpose of this paper is to show how to improve people's understanding of the dynamics of management innovation and intelligent drive environment. The method is as follows: First, through the intelligent text analysis, refine the essence of management innovation dynamic mechanism and intelligent driving environment. Then, it expounds the progress of research on the dynamic mechanism of management innovation. Finally, it discusses the construction of intelligent driving environment, and takes "physical, transaction, insight" and its application scenarios as examples. The result is: not only the research on the dynamic mechanism of management innovation and the concise expression of the construction of intelligent driving environment, that is, the result of intelligent text analysis. The significance lies in: from the perspective of the three kinds of connections: "physical, transactional, and epiphany", it gives a more accurate language understanding paradigm for both the management innovation dynamic mechanism and the intelligent driving environment.
\end{abstract}

Keywords: Management Innovation Dynamic Mechanism, Root Theory Analysis, Internet of Things, Business Contact Forms, Enlightened Connections, Intelligent Driving Environment

\section{Introduction}

\subsection{Background}

Since Schumpeter's innovative theory, entrepreneurship has been highlighted. This is a good echo with the market role emphasized by Adam Smith's "invisible hand". Combined with the practice of 40 years of China's reform and opening-up, we found that there is a management innovation problem for companies as legal drafters. [1]It involves not only the dynamic mechanism but also the driving environment. Therefore, the three teams in this study have come together from each other's perspectives. Below, we explain the focus of common concerns one by one. 


\subsection{Purpose}

The purpose of this paper is to show how to improve people's understanding of the management innovation dynamic mechanism and intelligent drive environment. The method is: First, through the intelligent text analysis, refine the essence of management innovation dynamic mechanism and intelligent driving environment. Then, it is on the management innovation dynamic mechanism research. Finally, it discusses the construction of intelligent driving environment, and takes "physical, transaction, insight" and its application scenarios as examples.

\section{Research on Management Innovation Dynamic Mechanism}

This study mainly answers two questions. First, what is the formation mechanism of the management innovation dynamic mechanism? What are the power and resistance, respectively? On this basis, try to construct a conceptual model of management innovation mechanics. Our theoretical group believes that we must first clarify the definition of the dynamic mechanism of management innovation.

\subsection{Theoretical Discussion}

As far as this study is concerned, the so-called management innovation dynamic mechanism mainly refers to the sum of the interconnection, interaction of various factors that promote the emergence of management innovation and the development of management innovation in the process of management innovation system. [2] [3] Based on the definition of management innovation dynamic mechanism, its characteristics can be summarized as follows: First, systemic, various dynamic elements of management innovation are interconnected, mutually restrictive, and interact. These elements constitute an organic system of management innovation. [4]The formation and development of the dynamic mechanism depends on various dynamic factors, but also on the systematic role between these elements. The second is holistic. Chinese classical philosophy advocates the idea of "the unity of nature and human". He believes that the world is a unified whole. Only by understanding the whole can grasp the overall connotation and extension. In the typical complex system of management system, the dynamic mechanism is a metaphysical abstract concept, which is similar to the so-called "Tao" of Laozi, which is deeply hidden behind the appearance and affects the operation of things. The third is rationale. Any artificial system has a certain purpose. The purpose of management innovation dynamic mechanism is to form a strong driving force and promote enterprises to carry out management innovation activities. To achieve this goal, various power elements must be coordinated and have relatively consistent purpose. The fourth is dynamic. It mainly means that the dynamic elements of management innovation are dynamic development rather than static. In different stages of management innovation development, the interaction and driving force between power elements are constantly changing. [5]

The management innovation dynamic mechanism has the following effects for an enterprise. The first is the driving role, which mainly refers to various internal and 
external factors that promote enterprise management innovation. Through interaction, it promotes the occurrence and development of enterprise management innovation, which is also the core of the management innovation dynamic mechanism. The second is the role of selection. It mainly refers to the management innovation process. In each period of time, the management innovation driving force and resistance are all working, thus forming a dynamic adjustment of termination, suspension and continuing management innovation. The dynamic mechanism of management innovation will be in the comparison of various choices, enterprises form a choice that is conducive to management innovation. The third is to strengthen the role. Through the management innovation dynamic mechanism, the effect of enterprises carrying out management innovation should be better than the result of not carrying out management innovation. Therefore, the management innovation has a positive strengthening function and promotes management innovation activities to continue to develop.

\subsection{Theoretical Construction}

This study uses a single case rooted research method to analyze the management innovation dynamic mechanism. In this analytical framework, the case collections are related to the utility and conclusions of the research, and the typicality of the case and the degree of access to the data need to be considered. [6]Based on the above factors, this study selected Taobao as a case.

This research collects more than 30 articles on the company's official website, news reports, academic literature, and corporate leadership interviews, and combines experiential research as the main material of this case. After data verification, the acquired information is highly consistent. In order to analyze the management innovation dynamic mechanism, this study based on the Taobao case to carry out rooted research, followed by open coding, associative coding, selective coding, story line analysis. [7]

Based on the existing literature, this study considers that the management innovation dynamic mechanism can be summarized as enterprise Model. (Figure 1).

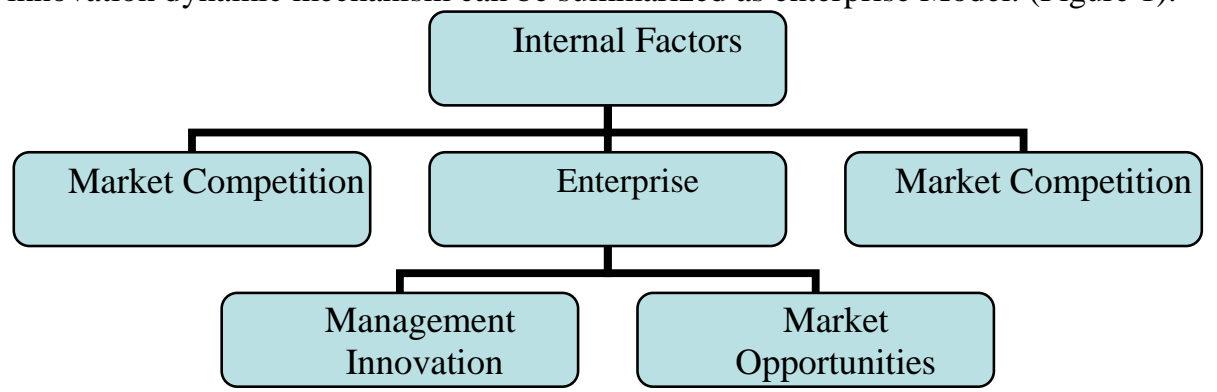

Figure 1 Management Innovation Dynamics Model diagram

Enterprises need to overcome the resistance of management innovation in order to promote the smooth implementation. The measures to overcome the resistance of management innovation are as follows: First, to strengthen incentives, the key to promoting innovation in management is to stimulate the initiative of employees 
through various means such as economic means; Formulate rules and regulations that are conducive to management innovation, standardize and sustain management innovation through system construction; third, increase investment, provide sufficient financial guarantee for management innovation, and provide good conditions for employees to implement management innovation. [8]

In the context of the technological revolution and industrial transformation, the internal mechanism of management innovation dynamics has the following characteristics: First, it is the most complex period of the external environment of the enterprise, and the fastest period of change.

The most direct and important motivation is managing innovation activities. Secondly, as the initiator, organizer and implementer of management innovation, the enterprise itself plays a central role in the whole process of management innovation. The enterprise itself pursues the interests and solves the actual needs of problems encountered in its development.[9] It is management innovation. The important force that can be implemented and deepened, the enterprise's own driving force for management innovation is an important part of enterprise management innovation.

On the basis of the above-mentioned exploration of the management innovation dynamic mechanism, combined with the system mechanics thought, we can try to construct the system motivation theory model. As mentioned above, the enterprise management innovation power system mainly includes external environmental factors and internal factors of enterprises. These factors interact and influence each other to jointly promote the management innovation of enterprises, and the innovation of enterprise management also has corresponding effects and indirect influence on management innovation. [10]

In order to express the relationship between these factors by mathematical formula, you can set:

The external environmental factor is $\mathrm{E}$ (environmental factor)

The internal factor of the enterprise is I (internal factor)

The overall benefit of the enterprise is B (benefit cost)

Enterprise management innovation is $\mathrm{M}$ (management innovation)

Management innovation system as function $\mathrm{f}$

Then there is the following expression or equation:

$$
M=f(E, I, B)
$$

Its system diagram has the following expression:

$$
\begin{aligned}
& M(t)=(X(t), Y(t)) \\
& X(t)=\{M(t), E(t), I(t), B(t)\} \\
& Y(t)=\{M(t) E(t), M(t) I(t), M(t) B(t), E(t) I(t), E(t) B(t), I(t) B(t)\}
\end{aligned}
$$

Analysis of the variables of the above expressions shows that the force of environmental factors is positively related to management innovation, so it can be expressed as follows: $\mathrm{M}(\mathrm{t}) \mathrm{E}(\mathrm{t}) \rightarrow+$, similarly: $\mathrm{M}(\mathrm{t}) \mathrm{I}(\mathrm{t}) \rightarrow+, \mathrm{M}(\mathrm{t}) \mathrm{B}(\mathrm{t}) \rightarrow+, \mathrm{E}(\mathrm{t}) \mathrm{I}(\mathrm{t})$ $\rightarrow+, \mathrm{E}(\mathrm{t}) \mathrm{B}(\mathrm{t}) \rightarrow+, \mathrm{I}(\mathrm{t}) \mathrm{B}(\mathrm{t}) \rightarrow+$. Therefore, a mapping expression can be established: $\mathrm{F}(\mathrm{t}): \mathrm{X}(\mathrm{t}) \rightarrow\{+\}$.Therefore, the model of enterprise management innovation dynamic mechanism can be expressed as: 


$$
P(t)=(X(t), Y(t), F(t))
$$

From the perspective of the direct impact on management innovation, the combination of external environmental factors such as market demand, competition, laws and regulations, etc., generates the power of enterprise management innovation. Through management innovation and self-development, enterprises also have a reactionary influence on the market and policies, and even guide market demand, intensify market competition, and seek the inclination of laws and regulations for enterprises (see Figure 2: Management innovation dynamic mechanism circuit diagram).

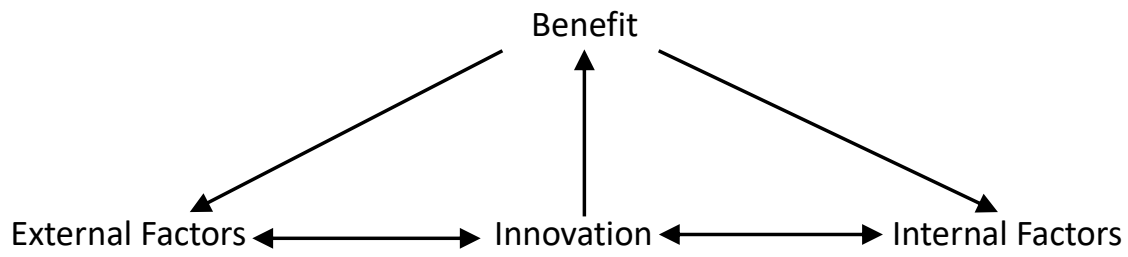

Figure 2 Management innovation dynamic mechanism circuit diagram

\section{The Creation of Intelligent Driving Environment}

Our operations team believes that it is important to focus on the innovative drive environment. They believe that information to big data, knowledge to AI, and go on with intelligence to a new paradigm iteration of object number fusion.

\subsection{Actual Build: Environment}

Our Sino-German cooperation team believes that as a result, such three sets of connections are brewing.

Table 1. A,B,C as the three groups of connections

\begin{tabular}{cccc}
\hline Phase & A. & B. & C. \\
\hline Size & MB/GB & TB/PB/ZB & TB/PB/ZB \\
Type & Structured data & Multi-Structured data & Unstable IOT data \\
Mode & One Size Fits All & No Size Fits All & Not Always Fit \\
Method & Scientific thinking & Artistic thinking & Design thinking \\
Program & Open source & Knowledge graph & Artificial intelligence \\
\hline
\end{tabular}

It can be seen from Table 1 that the three groups of A, B, and C are based on the "phase: the size of the data, the type of data, the mode of the data, the processing method, the thinking mode, the program" to produce corresponding development and linkage. 
A: Traditional database era: Small data, MB/GB; Less, structured data; Can be predetermined, Data is generated after the first data mode, Data mode is relatively fixed; One Size Fits All, commercial database; Scientific thinking, data convergence, copy and well done; open source big data tools combination application;

B: The age of informationization knowledge: big data, TB/PB/ZB; multi-, including structure, and the proportion of semi-structured and unstructured data is increasing; can not be predetermined, static data is the main mode After the data appears, it can be determined that the data model evolves as the data grows; No Size Fits All, there are relatively common open source solutions; artistic thinking, business agility is the focus, creative but doable; based on knowledge graph development;

$\mathrm{C}$ : Intelligence after future data fusion:

Very large data, $\mathrm{TB} / \mathrm{PB} / \mathrm{ZB}$, increased after cross-indexing; more, in addition to stable structured, semi-structured, unstructured data, and more extensive and unstable IOT data; streaming data, The proportion of real-time data is getting bigger and bigger, the data model is mixed, the physical digital fusion mode is fast iterative; Not Always Fit, it is necessary to develop new solutions to adapt to changes; design thinking, focusing on digital asset integration, innovation, sometimes Research; integration of overseas outstanding core artificial intelligence team.

\subsection{Actual optimization: intelligent}

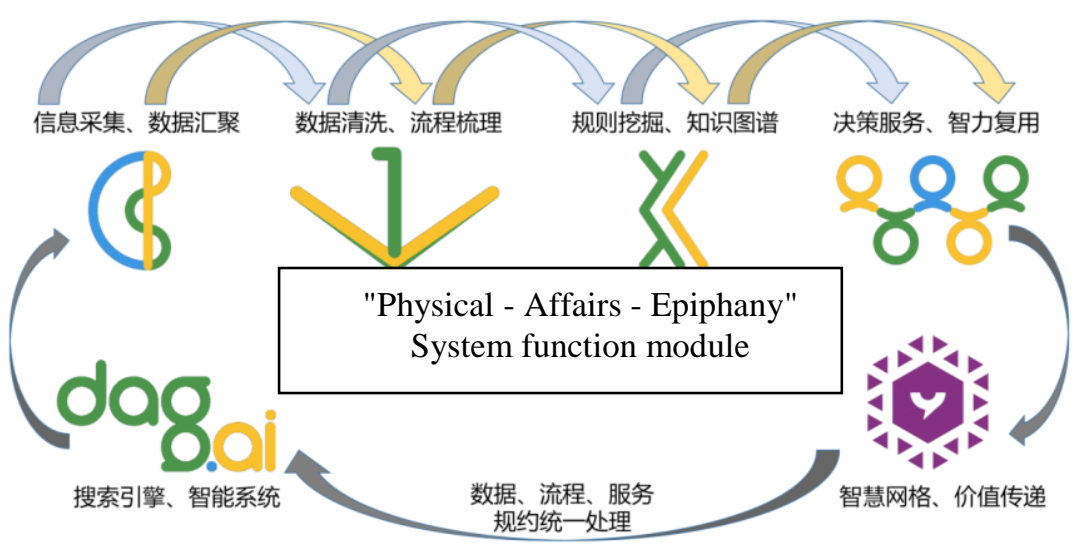

Figure 3 "Physical - Affairs - Epiphany" System function module ${ }^{11}$

Combined Figure 3 with Table 1, the intelligent graphic analysis of the ABC three-group connection can be advanced to a new level. In particular, combined with scientific thinking, artistic thinking and design thinking or innovative thinking, information collection and data aggregation; data cleaning, process grooming; rule mining, knowledge mapping; decision service, intelligence reuse; search engine,

\footnotetext{
${ }^{(1)}$ Hanglin Pan,etc., Knowledge Computing Architecture of Bio Industry, Bio Processing Business, 2018.1
} 
intelligent system; network, value transfer; data, processes, services, and statutes are handled uniformly.

Design is the forerunner and preparation of human purposeful innovation and creation of practical activities. It is itself creative, creative and innovative. Creative and innovative design has always been the forerunner and starting point of all human innovation and practice activities. Good design not only creates economic value, but also creates social, cultural and ecological values, which is one of the core factors for the competitiveness of enterprises and countries. [11] Design should be proven to be the "third wisdom" and ability of human beings not to be destroyed in the future, in addition to science and art.[12]Innovation is the basic and core feature of design. Without innovation, it is not a design. Innovative design is a kind of design method and technology. It specializes in the conceptual system of product innovation and studies various strategies, methods, techniques and tools to promote product innovation. [13] Social enterprises are the main path to achieve social innovation. Different from traditional enterprises, social enterprises are putting social responsibility first in the pursuit of profits. [14]

\section{Conclusion}

\subsection{Dynamic Mechanism and Driving Environment}

At present, there are not many researches on the enterprise management innovation dynamic mechanism, and it mainly focuses on the determination of the dynamic factors of management innovation, but the dynamic mechanism has not been systematically discussed. Based on the above research status, this study starts with the definition and connotation of the management innovation dynamic mechanism. Through the root analysis of Taobao management innovation, the system theory is used to conduct a more in-depth and systematic discussion on the management innovation dynamic mechanism, and try to build management innovation. The kinetic model has achieved research results with certain value. First, on the basis of the existing research literature, clarify the definition and connotation of the dynamic mechanism of management innovation, and expound the definition of management innovation dynamics in the perspective of this research. Second, from the Taobao management innovation practice, in the absence of any pre-requisites, through the grounded theory analysis, the case is open-coded, correlated coding, selective coding, story line analysis, and the management innovation dynamic factors are analyzed. Thirdly, on the basis of grounded analysis, research on the external environmental power and internal dynamics of the enterprise, and try to construct a dynamic model of management innovation

\subsection{Significance}

Combining the "Physical-Affairs-Epiphany" System function module to construct a driving environment is unique. Breaking through the new technologies of German Industry 4.0 and the new generation of artificial intelligence in the United States and 
Japanese robots, as another kind of driving environment, the driving environment function brought about by China's future management innovation cannot be underestimated. Nevertheless, whether it is within the enterprise or the domestic research on the management innovation dynamic mechanism, it has special significance.

Next, we will do further research on the relationship between "management innovation, dynamic mechanism and driving environment" and "economic innovation, smart integration (involving knowledge-based block-chains), and financial communication (involving virtual currency-based block-chains)". In particular, it is a systematic study of the relationship between Schumpeter's "economic innovation" and Adam Smith's "invisible hand" with "market innovation." It is also necessary to use the "human brain and computer (two kinds of hardware biological and physical)" and "the intellectual research in psychology and the artificial intelligence research in computer science" (two kinds of software - in the scope of logic, mathematics and linguistics can be combined into one) "deep questions, put on the agenda.[15][16]

\section{References}

1. Lü Yuhui. What are the reasons for the innovation motivation of state-owned enterprise managers? [J]. Operating and Management, 2010(2):10-11.

2. Zhang Guoqiang, Feng Dingzhu, Wei Jujin. Discussion on Dynamic Theory of Enterprise Technology Innovation[J]. Technology and Innovation Management, 2010, 31(1): 23-26.

3. Hu Zhongrui. Research on Dynamic Mechanism and Model of Enterprise Green Technology Innovation [D]. Central South University, 2006.

4. Lewin K. A Dynamic Theory of personality-Selected papers[M]. Read Books Ltd, 2013.

5. Jean Messonav. Group Dynamics [M]. The Commercial Press, 1997.

6. Zhang Jiajun. The Enlightenment of Grounded Theory to Curriculum Research[J]. Journal of Comparative Education, 2010, 10: 81-85.

7. Strauss A L. Qualitative analysis for social scientists [M]. Cambridge University Press, 1987.

8. Lü Yuhui. Factor Flow in Enterprise Technology Innovation System[J]. Science and Technology Management Research, 2012, 32(4): 9-11.

9. Chen Yujing. On Musical Therapy and Freud's Psychoanalysis [J]. Artistic Ocean, 2010(2):48-48.

10. Wang Longwei, Li Wei, Wang Zhuliang. Research on the Motivation and Management of Organizational Inertia [J]. Forecast, 2004, 23(6):1-4.

11. Lu Yongxiang (National People's Congress Standing Committee), Rethinking on Design Evolution, Mechanical Engineering Trends, 2014, Issue 2 (Total Issue 171), p03-05

12. Liu Guanzhong (Tsinghua University Academy of Fine Arts), design is the "third wisdom" that humanity will not be destroyed in the future, Mechanical Engineering Trends, No. 2, 2014 (Total 171), p06-23

13. Feng Peien (Zhejiang University), Design, Innovation and Development Environment, Mechanical Engineering Trends, No. 2, 2014 (Total Issue 171), p24-28

14. Liu Yuhui (Hong Kong Polytechnic University), Innovative Design and New Value: System Design Thinking for Transferring Economy, Mechanical Engineering Trends, No. 2, 2014 (Total Issue 171), p9-31 
15. Zou, X.; Zou, S.; Ke, L. Fundamental Law of Information: Proved by Both Numbers and Characters in Conjugate Matrices. Proceedings 2017, 1, 60.

16. Zou, X., Zou, S.: Bilingual information processing method and principle. J. Comput. Appl. Softw. (11) (2015) 